\title{
ASXL1 mutations in Chinese patients with essential thrombocythemia
}

\author{
YAN-BO NIE ${ }^{1 *}$, MENG SUN $^{2 *}$, COLIN K. HE ${ }^{3}$, MAN-KAI JU ${ }^{4}$, FU-LING ZHOU ${ }^{1}$, SAN-YUN WU ${ }^{1}$, YI ZHOU ${ }^{1}$, \\ LI LIU $^{1}$, HUI SHEN ${ }^{1}$, TING-TING HUANG ${ }^{1}$, PAN LIU ${ }^{5}$, YING XU ${ }^{6}$, LIANG SHAO ${ }^{1}$ and XUE-LAN ZUO ${ }^{1}$ \\ Departments of ${ }^{1}$ Hematology and ${ }^{2}$ Gastroenterology, Zhongnan Hospital of Wuhan University, Wuhan, Hubei 430071, \\ P.R. China; ${ }^{3}$ Stego Tech LLC, Audubon, PA 19403, USA; ${ }^{4}$ Department of Hematology, Institute of Hematology and \\ Hospital of Blood Diseases Chinese Academy of Medical Sciences and Peking Union Medical College, Beijing 300000; \\ ${ }^{5}$ Department of Immunology, School of Basic Medical Sciences, Wuhan University, Wuhan, Hubei 430071; \\ ${ }^{6}$ Department of Hematology, The Fifth Hospital of Wuhan, Wuhan, Hubei 430050, P.R. China
}

Received July 15, 2017; Accepted November 17, 2017

DOI: $10.3892 /$ etm.2018.5939

\begin{abstract}
Essential thrombocythemia (ET) is characterized by thrombotic and hemorrhagic events. The association of clinical characteristics of Chinese ET patients and additional sex combs like 1 (ASXL1) mutations in these patients has remained to be elucidated. In the present study, 72 newly diagnosed Chinese ET patients were enrolled to determine ASXL1 mutations. Mutations in ASXL1, Janus kinase (JAK)2, calreticulin (CALR) and myeloproliferative leukemia (MPL) genes were detected using Sanger sequencing, and data were statistically analyzed. The frequencies of ASXL1, JAK2 V617F, CALR and MPL W515 mutations in ET patients were $19.4 \%$ (14/72), 29.2\% (21/72), 31.9\% (23/72) and 0\% (0/72), respectively. Of note, $28 \mathrm{ET}$ patients $(38.9 \%)$ were negative for JAK2, CALR and MPL mutations; these patients were classified as triple-negative (TN). The frequency of ASXL1 mutations in patients with JAK2 V617F, CALR and TN mutations was $23.8 \%(5 / 21), 21.7 \%(5 / 23)$ and $14.3 \%(4 / 28)$, respectively. ASXL1-mutant patients exhibited significant propensities for thrombotic events compared with the ASXL1 wild-type (wt) cohort (42.9 vs. $12.1 \%$; $\mathrm{P}=0.021$ ). In addition, JAK2 V617F-mutant patients had a higher mean age compared with CALR-mutant (64.76 vs. 52.96 years; $\mathrm{P}=0.008)$ or $\mathrm{TN}$ patients (64.76 vs. 51.14 years; $\mathrm{P}=0.002)$. Furthermore, more white blood cells in the peripheral blood (PB) were observed
\end{abstract}

Correspondence to: Dr Liang Shao or Professor Xue-Lan Zuo, Department of Hematology, Zhongnan Hospital of Wuhan University, 169 Donghu Road, Wuhan, Hubei 430071, P.R. China

E-mail: liangsmd@163.com

E-mail: zuoxuelan2004@126.com

${ }^{*}$ Contributed equally

Key words: essential thrombocythemia, calreticulin mutation, Janus kinase 2 V617F mutation, triple-negative, thrombotic events in JAK2 V617F-mutant patients compared with those in TN patients $\left(12.40\right.$ vs. $\left.8.20 \times 10^{9} / 1 ; \mathrm{P}=0.02\right)$. In addition, CALR-mutant patients exhibited more platelets (PLT) in PB than JAK2 V617F-mutant patients (787.91 vs. 562.17x10 $/ 1$; $\mathrm{P}=0.047)$. TN patients had a significantly lower incidence of clinical symptoms, including dizziness, palpitation and chest congestion compared with CALR- or JAK2 V617F-mutant patients (14.1 vs. $39.1 \%$; $\mathrm{P}=0.043$ and 14.1 vs. $38.1 \% ; \mathrm{P}=0.050)$. No significant difference in progression-free survival was observed between ASXL1-mutant and ASXL1-wt patients $(\mathrm{P}=0.590)$. In conclusion, ASXL1-mutant ET patients are prone to experiencing thrombotic events. There was no significant difference in the occurrence of thrombotic events among CARL-mutant, JAK2 V617F-mutant and TN patients. Furthermore, ASXL1-mutant/TN patients exhibited a higher number of PLT than ASXL1/JAK2 V617F-double mutant patients. Therefore, ASXL1 mutations may be a risk factor for the occurrence of thrombotic events in ET patients.

\section{Introduction}

Essential thrombocythemia (ET), a clonal hematological disorder, is characterized by excessive proliferation of myeloid progenitor cells (1). The absolute number of platelets in peripheral blood (PB) of ET patients is frequently $>1,000 \times 10^{9} / 1$ (2). The incidence of ET is $\sim 41 \%$ worldwide $(1,2)$. The most common symptoms are usually associated with thrombosis and hemorrhage. With regard to the clinical course, ET is relatively indolent; however, the majority of ET patients are unlikely to be completely cured. In addition, in $<5 \%$ of affected patients, ET finally develops into acute myeloid leukemia (1-3). The additional sex combs-like 1 (ASXL1) gene, located in chromosome $20 \mathrm{q} 11$, has been reported to be involved in epigenetic regulation and may be utilized for monitoring tumor stem or progenitor cell self-renewal or differentiation (4-6). It has been identified that ASXL1 mutations are associated with hematologic disorders, including aplastic anemia, myeloproliferative neoplasms (MPNs), acute myeloid leukemia (AML), myelodysplastic syndrome (MDS) and chronic myelomonocytic leukemia 
(CMML) (7-11). In addition, in primary myelofibrosis (PMF) patients, ASXL1 mutations were identified to be correlated with a shorter overall survival (OS) $(12,13)$. The frequencies of ASXL1 mutations were reported to be $\sim 23,5.6$ and $3.5 \%$ in the MPN sub-types primary myelofibrosis (PMF), ET and polycythemia vera (PV), respectively (14-16). Furthermore, ASXL1 mutations include not only point mutations, but frameshifts and nonsense mutations, of which the most common ones are frameshift mutations (c.1934dupG), accounting for nearly $50 \%$ of the reported ASXL1 mutations (14-16). Furthermore, in patients with ET, the frequency of Janus kinase (JAK)2 V617F, calreticulin (CALR) and myeloproliferative leukemia (MPL) W515 mutations was reported to be $\sim 50,<5$ and $\sim 11 \%$ in Western countries (17-20) and $\sim 60, \sim 30$ and $<5 \%$ in China, respectively (21-23). However, the occurrence and precise roles of ASXL1 mutations in Chinese ET patients have remained elusive. In the present study, the occurrence of ASXL1 in 72 newly diagnosed ET patients was assessed and its clinical significance in ET was further investigated.

\section{Materials and methods}

Patients and selection criteria. A total of 72 ET patients diagnosed at Zhongnan Hospital of Wuhan University (Wuhan, China) and the Fifth Hospital of Wuhan (Wuhan, China) between April 2001 and June 2016 were enrolled in the present study. Pregnant females or patients with other malignancies were excluded. The entire cohort included 32 males and 40 females. The mean age of the entire cohort was 55.79 (range, 10-95 years). The diagnosis of ET was based on the published 2016 criteria of the World Health Organization (3). All patients had a sustained blood platelet (PLT) count of $>450 \times 10^{9} / 1$ without any treatment; the cut-off value of PLT count is $\geq 550 \times 10^{9} / 1$. Other possible myeloid malignancies were excluded, including PV, PMF, chronic myeloid leukemia and MDS. The majority of patients had exhibited pathogenic mutations in bone marrow cells, including JAK2 V617F, CALR and MPL W515. Patients were expected to have no causes of secondary thrombocytosis, normal iron stores and a bone marrow smear exhibiting increased megakaryocytes and displaying a spectrum of morphology with prominent large hyperlobulated forms. Informed written consent was obtained from patients prior to sample collection, in accordance with the Declaration of Helsinki, and clinical research was approved by the Ethics Committee of Zhongnan Hospital of Wuhan University and the Fifth Hospital of Wuhan.

Analysis of gene mutations. Bone marrow samples of the 72 ET patients were collected from Zhongnan Hospital of Wuhan University and The Fifth Hospital of Wuhan. Samples were stored at $4^{\circ} \mathrm{C}$ until DNA extraction with a TIANamp Blood DNA kit (Tiangen, Beijing, China). The concentration and purity of the DNA samples $(1.5 \mu \mathrm{l})$ was determined using an ultraviolet spectrophotometer (Biophotometer; Eppendorf, Hamburg, Germany) by measuring the optical density at 260 vs. $280 \mathrm{~nm}$ absorbance, and the ratio was 1.8-2.0 for pure DNA.

Polymerase chain reaction (PCR) mixture contained $25 \mu \mathrm{l}$ DreamTaq Hot Start Green PCR Master Mix (2X; cat. no. K9021; Thermo Fisher Scientific, Inc., Waltham, MA, USA), $0.8 \mu \mathrm{M}$ forward primer, $0.8 \mu \mathrm{M}$ reverse primer,
200 ng template DNA and nuclease-free water filled up to a final volume of $50 \mu \mathrm{l}$. The primers for JAK2, MPL, CALR and ASXL1 are listed in Table I. The PCR conditions were as follows: Initial denaturation at $95^{\circ} \mathrm{C}$ for $3-5 \mathrm{~min}$, followed by 35 cycles at $94^{\circ} \mathrm{C}$ for $30 \mathrm{sec}, 55^{\circ} \mathrm{C}$ for $30 \mathrm{sec}$ and $72^{\circ} \mathrm{C}$ for $1 \mathrm{~min}$, and a final extension at $72^{\circ} \mathrm{C}$ for $5 \mathrm{~min}$.

Extraction and sequencing analysis of the PCR products was performed by Sangon Biotech (Shanghai, China). The Sanger DNA sequencing method was applied using an (ABI 3730XL; Applied Biosystems; Thermo Fisher Scientific, Inc.). The sequencing results were analyzed by Chromas 2.31 software (Technelysium Pty, Ltd., Brisbane, Qld, Australia) and the sequences were compared using Sequence scanner software version 1.0 (Applied Biosystems; Thermo Fisher Scientific, Inc.).

Response criteria. Clinical response criteria for ET patients were according to those established by the European Leukemia Net consensus conference (2). In brief, complete response $(\mathrm{CR})$, partial response (PR) and no response (NR) were defined as follows: CR, PB PLT $\leq 400 \times 10^{9} / 1$, no disease-associated symptoms, normal spleen size on imaging and $\mathrm{PB}$ white blood cell (WBC) count $\leq 10 \times 10^{9} / 1$; PR, no fulfillment of CR criteria, PB PLT $\leq 600 \times 10^{9} / 1$ or PLT decrease by $>50 \%$ from baseline; NR, no fulfillment of CR and PR criteria.

Prognostic scoring for ET. Prognostic scoring for ET patients was according to the International Prognostic Scoring for Essential Thrombocythemia-thrombosis (IPSET-T) (24). In brief, the scoring system, including several invariables (1 point for WBC count $\geq 11 \times 10^{9} / 1$ or history of thrombosis and 2 points for age $\geq 60$ years), was used to stratify patients into low-risk ( 0 point), intermediate-risk (1-2 points) or high-risk (3-4 points) groups.

Statistical analysis. Numeric variables are expressed as the median or mean \pm standard deviation, while categorical variables were expressed as counts (n) and frequencies (\%). Comparisons of enumeration data between different groups were performed using the chi-square test, while comparison of measurement data was performed using the Student's t-test or analysis of variance. Progression-free survival (PFS) was calculated by Kaplan-Meier survival analysis and respective curves were drawn. A multivariable Cox proportional hazards regression was used to model the duration and the incidence of PFS. All statistical analyses were performed with SPSS version 19.0 (IBM Corp., Armonk, NY, USA). All P-values are two-tailed and statistical significance was set as $\mathrm{P}<0.05$. The risk factors of disease progression were analyzed by principal component analysis (PCA) and permutation multivariate analysis of variance (PERMANOVA), which is more robust regarding correlations and heterogeneous variance.

\section{Results}

Characteristics of patients and ET. The clinical characteristics of the cohort of ET patients are summarized in Table II and those of ASXL1-mutant patients are listed in Table III. With regard to risk stratification based on IPSET-T, 55.6\% (40/72), $15.3 \%$ (11/72) and 29.2\% (21/72) of the cohort were 
Table I. Sequences of oligonucleotide primers used for sequencing of the coding regions of ASXL1, JAK2, MPL and CALR genes.

\begin{tabular}{lll} 
Amplicon & \multicolumn{1}{c}{ Forward 5'-3' } & \multicolumn{1}{c}{ Reverse 5'-3' } \\
\hline ASXL1 exon 12 PCR1 & CCGGCTTGAAGATCGTCAGT & AGGCTGCTCCACTAATCTCT \\
ASXL1 exon 12 PCR2 & AGAGGACCTGCCTTCTCTGA & GGCTCAACAGATGGTATGTG \\
ASXL1 exon 12 PCR3 & GGAACTGGCCAAGCTCTTGA & TCCTTGTCCACCGAAGATCC \\
ASXL1 exon 12 PCR4 & ACTGAGTCCTCACGGTGAGT & CAGCTATCTGGCAGAAGAGG \\
ASXL1 exon 12 PCR5 & CCACGATGACAGCATGTCAG & CATTCTTGACGCTGCCAACA \\
ASXL1 exon 12 PCR6 & ATGCCTCTTCCTGCTGAGAT & GTGCTCCTGCCTAAAGAGTA \\
JAK2-exon 14 & GGGTTTCCTCAGAACGTTGA & TCATTGCTTTCCTTTTTCACAA \\
JAK2-exon 12 & CTCCTCTTTGGAGCAATTCA & GAGAACTTGGGAGTTGCGATA \\
MPL W515 & TGGGCCGAAGTCTGACCCTTT & ACAGAGCGAACCAAGAATGCCTGT \\
CALR-exon 9 & ACAACTTCCTCATCACCAACG & GGCCTCAGTCCAGCCCTG
\end{tabular}

As the sequence of ASXL1 exon12 is very long, PCR analyses were performed following the division of the sequence in six. JAK, Janus kinase; CALR, calreticulin; ASXL1, additional sex combs like 1; MPL, myeloproliferative leukemia; PCR, polymerase chain reaction.

Table II. Comparison of laboratory parameters and clinical characteristics of essential thrombocythemia patients stratified by their ASXL1 mutational status.

\begin{tabular}{|c|c|c|c|}
\hline Parameter/characteristic & ASXL1-mutant $(n=14)$ & ASXL1-wt (n=58) & P-value \\
\hline Age at diagnosis & $52.5 ; 51.1 \pm 17.5$ & $57 ; 56.8 \pm 13.7$ & 0.187 \\
\hline Female sex & $8(57.1)$ & $32(55.1)$ & 1.000 \\
\hline WBC count, $\times 10^{9} / 1$ & $8.24 ; 9.0 \pm 3.56$ & $8.83 ; 9.8 \pm 5.48$ & 0.643 \\
\hline Hemoglobin, g/l & $135.5 ; 135.4 \pm 23.0$ & $132.9 ; 136.7 \pm 30.4$ & 0.881 \\
\hline Platelet count, $\mathrm{x} 10^{9} / 1$ & $680 ; 586 \pm 276.7$ & $671.5 ; 702 \pm 367.6$ & 0.274 \\
\hline Bleeding & $0(0)$ & $4(6.9)$ & 0.718 \\
\hline Dizziness, palpitation, chest congestion & $2(14.3)$ & $18(31.0)$ & 0.356 \\
\hline Numbness & $0(0)$ & $7(12.1)$ & 0.387 \\
\hline Feeble & $2(14.3)$ & $8(13.8)$ & 1.000 \\
\hline Splenomegaly/hepatomegaly & $2(14.3)$ & $7(12.1)$ & 1.000 \\
\hline \multicolumn{4}{|l|}{ Previous history } \\
\hline Hypertension & $1(7.1)$ & $12(20.7)$ & 0.426 \\
\hline Coronary heart disease & $2(14.3)$ & $5(8.6)$ & 0.889 \\
\hline
\end{tabular}

Values are expressed as the 'median; mean (standard deviation)' or as 'n (\%)'. WBC, white blood cell; ASXL1, additional sex combs like 1; wt, wild-type.

low-, intermediate- and high-risk patients, respectively. No significant difference was identified in the ASXL1-mut and -wt groups among the low-, intermediate- and high-risk stratification $(\mathrm{P}=0.968$; Table IV). In the entire cohort of ET patients, the occurrences of JAK2 V617F, CALR and MPL W515 mutations were 29.2\% (21/72), 31.9\% (23/72) and 0\% (0/72), respectively, and 'triple-negative' (TN) ET patients accounted for $38.9 \%$ (28/72) of the entire cohort (Table V). Patients with JAK2 V617F mutations had a significantly higher WBC count in the PB compared with that in $\mathrm{TN}$ patients $\left(12.40 \pm 7.80\right.$ vs. $\left.8.20 \pm 2.17 \times 10^{9} / 1 ; \mathrm{P}=0.02\right)$. However, the difference in the $\mathrm{WBC}$ count was insignificant between patients with JAK2 V617F and CALR mutations (12.40 vs. 8.82x10\%/1; $\mathrm{P}=0.06)$. TN and CALR-mutant cohorts also exhibited an insignificant difference in WBC count (8.20 vs. 8.82x10 1 ; $\mathrm{P}=0.457)$. Of note, $\mathrm{TN}$ patients had higher hemoglobin (HB) than CALR-mutant patients (140.37 vs. $129.29 \mathrm{~g} / \mathrm{l} ; \mathrm{P}=0.074)$. The cut-off value of $\mathrm{HB}$ is $\geq 190 \mathrm{~g} / \mathrm{l}$ CALR-mutant patients exhibited a higher PLT count than the JAK2 V617F-mutant cohort (787.91 vs. $\left.562.17 \times 10^{9} / 1 ; \mathrm{P}=0.047\right)$. Compared with TN patients, CALR-mutant and JAK2 V617F-mutant patients had a significantly higher incidence in common symptoms, including dizziness, palpitation and chest congestion (39.1 and 38.1 vs. $14.3 \% ; \mathrm{P}=0.043$ and 0.05 , respectively). The occurrence of splenomegaly/hepatomegaly did not significantly differ among TN, CALR-mutant and JAK2 V617F-mutant patients (28.6 vs. $10.7 \%$; $\mathrm{P}=0.221$ and 28.6 vs. $8.7 \%$; $\mathrm{P}=0.188$; Table V). However, a significant difference was present in 
Table III. Clinical and molecular characteristics of ASXL1-mutant patients with essential thrombocythemia.

\begin{tabular}{|c|c|c|c|c|c|c|c|}
\hline Patient ID & $\begin{array}{c}\text { Age } \\
\text { (years) }\end{array}$ & Sex & $\begin{array}{c}\text { ASXL1 } \\
\text { mutant type }\end{array}$ & $\begin{array}{l}\text { Characteristic } \\
\text { mutations }\end{array}$ & $\begin{array}{c}\text { FU } \\
\text { (months) }\end{array}$ & $\begin{array}{c}\text { OS } \\
\text { (months) }\end{array}$ & $\begin{array}{c}\text { Survival } \\
\text { status }\end{array}$ \\
\hline $\mathrm{P} 1$ & 66 & M & G652S & CALR positive & 20 & 20 & Alive \\
\hline $\mathrm{P} 2$ & 20 & M & G652S & $\mathrm{TN}$ & 29 & 29 & Alive \\
\hline P3 & 54 & $\mathrm{~F}$ & G652S & CALR positive & 23 & 23 & Alive \\
\hline P4 & 51 & $\mathrm{~F}$ & G652S & CALR positive & 24 & 24 & Alive \\
\hline P5 & 44 & M & G652S & $\mathrm{TN}$ & 37 & 37 & Alive \\
\hline P6 & 59 & $\mathrm{~F}$ & G652S & $\mathrm{TN}$ & 15 & 15 & Alive \\
\hline P7 & 58 & $\mathrm{~F}$ & G652S & CALR positive & 23 & 23 & Alive \\
\hline P8 & 41 & M & G652S & CALR positive & 19 & 19 & Alive \\
\hline P9 & 10 & $\mathrm{M}$ & G652S & JAK2V617F positive & 35 & 35 & Alive \\
\hline P10 & 65 & M & G652S & JAK2V617F positive & 39 & 39 & Alive \\
\hline P11 & 60 & M & G652S & JAK2V617F positive & 103 & 103 & Alive \\
\hline P12 & 73 & $\mathrm{~F}$ & G652S & JAK2V617F positive & 63 & 63 & Alive \\
\hline P13 & 58 & $\mathrm{~F}$ & G652S & $\mathrm{TN}$ & 150 & 150 & Alive \\
\hline P14 & 56 & $\mathrm{~F}$ & G652S & JAK2V617F positive & 25 & 25 & Alive \\
\hline
\end{tabular}

TN, triple-negative; JAK, Janus kinase; CALR, calreticulin; ASXL1, additional sex combs like 1; M, male; F, female; FU, follow-up time; OS, overall survival; MPL, myeloproliferative leukemia.

Table IV. Thrombotic events, IPSET-T score and treatment response of ET patients.

\begin{tabular}{lcc}
\hline Parameter & ASXL1-mutant $(\mathrm{n}=14)$ & ASXL1-wt (n=58) \\
\hline Thrombosis/thromboembolisms & $6(42.9)$ & $7(12.1)$ \\
IPSET-T score & & $33(56.9)$ \\
Low-risk (0-1) & $7(50.0)$ & $7(12.1)$ \\
Intermediate-risk (2) & $4(28.6)$ & $18(31.0)$ \\
High-risk ( $\geq 3.0)$ & $3(21.4)$ & $21(36.2)$ \\
Treatment response & & $22(37.9)$ \\
CR & $6(42.9)$ & $15(25.9)$ \\
PR & $5(35.7)$ & 0.968 \\
NR & $3(21.4)$ &
\end{tabular}

Values are expressed as $\mathrm{n}(\%)$. CR, complete response; PR, partial response; NR, no response; ASXL1, additional sex combs like 1; wt, wild-type; IPSET-T, International Prognostic Scoring for ET thrombosis; ET, essential thrombocythemia.

the IPSET-T score and treatment response among the TN, CALR-mutant and JAK2 V617F-mutant patients $(\mathrm{P}=0.001$ and $\mathrm{P}=0.015$, respectively). There was no significant difference in the occurrence of thrombotic events among CARL-mutant, JAK2 V617F-mutant and TN cohorts (Table VI).

Frequencies and sub-types of ASXL1 mutations. ASXL1 mutations were detected in $19.4 \%$ (14/72) of ET patients. The median age was not significantly different between ASXL1-mutant and ASXL1-wild-type (wt) patients $(52.5 \pm 17.50$ vs. $57 \pm 13.70$ years, $\mathrm{P}=0.187$; Table II). The most common mutation in ASXL1 was the missense mutation [c.G1954A(p.Gly652Ser)]. However, the frameshift mutation [c.1934dupG(p.Gly646TrpfsX12)], a 23-bp deletion as the cause of a nonsense alteration, was not detected. Furthermore, a common synonymous mutation, namely that in a coding single nucleotide polymorphism [c.T3759C (p.S1253S); frequency, 27.7\%], was detected.

Comparison of laboratory parameters and clinical characteristics of ET patients. Statistical analysis indicated that ASXL1-mutant patients had obvious propensities for thrombotic events as compared with the ASXL1-wt cohort (42.9 vs. $12.1 \%$; $\mathrm{P}=0.021$; Table IV). However, the frequencies of splenomegaly/hepatomegaly were similar between ASXL1-mutant and ASXL1-wt patients. In addition, ASXL1-mutant cohorts still exhibited a similar incidence in common clinical symptoms, including dizziness, palpitation and chest congestion, compared with ASXL1-wt patients ( 14.3 vs. $31 \%$; $\mathrm{P}=0.356)$. There was no significant difference in the incidence in the history of coronary heart disease and hypertension between ASXL1-mutant and 
Table V. Comparison of laboratory parameters and clinical characteristics between essential thrombocythemia patients stratified by their mutation status of CALR, JAK2 and MPL.

\begin{tabular}{|c|c|c|c|c|c|c|c|}
\hline Parameter/characteristic & $\begin{array}{l}\text { Group A } \\
\text { TN } \\
(n=28)\end{array}$ & $\begin{array}{c}\text { Group B } \\
\text { CALR-mutant } \\
(\mathrm{n}=23)\end{array}$ & $\begin{array}{c}\text { Group C } \\
\text { JAK2 } \\
\text { V617F-mutant } \\
(n=21)\end{array}$ & $\begin{array}{c}\text { Total } \\
\text { P-value }\end{array}$ & $\begin{array}{l}\text { P-value } \\
\text { (A vs. B) }\end{array}$ & $\begin{array}{l}\text { P-value } \\
\text { (A vs. C) }\end{array}$ & $\begin{array}{l}\text { P-value } \\
\text { (B vs. C) }\end{array}$ \\
\hline Age at diagnosis (years) & $\begin{array}{c}55 ; \\
51.14 \pm 12.56\end{array}$ & $\begin{array}{c}52 \\
52.96 \pm 10.61\end{array}$ & $\begin{array}{c}66 \\
64.76 \pm 16.99\end{array}$ & 0.002 & 0.585 & 0.002 & 0.008 \\
\hline Female & $16(57.1)$ & $13(56.5)$ & $11(52.4)$ & 0.940 & 0.964 & 0.740 & 0.783 \\
\hline ASXL1 mutations & $4(14.3)$ & $5(21.7)$ & $5(23.8)$ & 0.751 & 0.745 & 0.632 & 1.000 \\
\hline WBC count, $\times 10^{9} / 1$ & $\begin{array}{c}8.70 \\
8.20 \pm 2.17\end{array}$ & $\begin{array}{c}8.38 \\
8.82 \pm 3.73\end{array}$ & $\begin{array}{c}10.59 \\
12.40 \pm 7.80\end{array}$ & 0.010 & 0.457 & 0.02 & 0.066 \\
\hline Hemoglobin, g/l & $\begin{array}{c}138.50 \\
140.37 \pm 22.41\end{array}$ & $\begin{array}{c}130.00 \\
129.29 \pm 20.48\end{array}$ & $\begin{array}{c}131.30 \\
138.90 \pm 41.88\end{array}$ & 0.361 & 0.074 & 0.885 & 0.349 \\
\hline Platelet count, $\times 10^{9} / 1$ & $\begin{array}{c}672.00 \\
706.79 \pm 324.49\end{array}$ & $\begin{array}{c}785.00 \\
787.91 \pm 327.94\end{array}$ & $\begin{array}{c}485.00 \\
562.17 \pm 403.82\end{array}$ & 0.105 & 0.381 & 0.171 & 0.047 \\
\hline \multicolumn{8}{|l|}{ Signs/symptoms } \\
\hline Bleeding & $2(7.1)$ & $1(4.3)$ & $1(4.8)$ & 1.000 & 1.000 & 1.000 & 1.000 \\
\hline $\begin{array}{l}\text { Dizziness, palpitation, chest } \\
\text { congestion }\end{array}$ & $4(14.3)$ & $9(39.1)$ & $8(38.1)$ & 0.086 & 0.043 & 0.050 & 0.944 \\
\hline Numbness & $0(0)$ & $3(13.0)$ & $4(19.0)$ & 0.038 & 0.170 & 0.060 & 0.896 \\
\hline Feebleness & $3(10.7)$ & $3(13.0)$ & $4(19.0)$ & 0.699 & 1.000 & 0.680 & 0.896 \\
\hline Splenomegaly/hepatomegaly & $3(10.7)$ & $2(8.7)$ & $6(28.6)$ & 0.159 & 1.000 & 0.221 & 0.188 \\
\hline \multicolumn{8}{|l|}{ Previous history } \\
\hline Hypertension & $7(25.0)$ & $2(8.7)$ & $4(19.0)$ & 0.295 & 0.250 & 0.882 & 0.576 \\
\hline Coronary heart disease & $2(7.1)$ & $3(13.0)$ & $2(9.5)$ & 0.882 & 0.817 & 1.000 & 1.000 \\
\hline
\end{tabular}

Values are expressed as the 'median; mean (standard deviation)' or as 'n (\%)'. WBC, white blood cell; ASXL1, additional sex combs like 1; wt, wild-type; TN, triple-negative; JAK, Janus kinase; CALR, calreticulin; MPL, myeloproliferative leukemia.

Table VI. Thrombotic events, IPSET-T score and treatment response of essential thrombocythemia patients stratified by their mutation status of CALR, JAK2 and MPL.

\begin{tabular}{lccc}
\hline Parameter & TN $(\mathrm{n}=28)$ & CALR-mutant $(\mathrm{n}=23)$ & JAK2 V617F-mutant $(\mathrm{n}=21)$ \\
\hline Thrombosis/ thromboembolism & $5(17.9)$ & $5(21.7)$ & $3(14.3)$ \\
IPSET-T score & & & 0.864 \\
Low-risk (0-1) & $22(78.6)$ & $18(78.3)$ & 0.001 \\
Intermediate-risk (2) & $4(14.3)$ & $0(0)$ & $7(33.3)$ \\
High-risk ( $\geq 3)$ & $2(7.1)$ & $5(22.7)$ & $14(66.7)$ \\
Treatment response & & & $13(61.9)$ \\
CR & $9(32.1)$ & $5(21.7)$ & $6(28.6)$ \\
PR & $11(39.3)$ & $10(43.5)$ & $2(9.5)$ \\
NR & $8(28.6)$ & $8(34.8)$ & 0.015 \\
\hline
\end{tabular}

Values are expressed as n (\%). CR, complete response; PR, partial response; NR, no response; TN, triple-negative; JAK, Janus kinase; CALR, calreticulin; IPSET-T, International Prognostic Scoring for ET thrombosis; ET, essential thrombocythemia.

ASXL1-wt cohorts (14.3 vs. 8.6\%; $\mathrm{P}=0.889$; and 20.7 vs. $7.1 \%$; $\mathrm{P}=0.426)$. No significant difference in the WBC and PLT count, as well as HB levels was observed between ASXL1-mutant and ASXL1-wt patients (Table III). Of note, the ASXL1-mutant/TN cohort (median age and standard deviation, $51 \pm 18.17$ years) was younger at diagnosis than the ASXL1-wt/JAK2V617F-mutant cohort (median age and standard deviation, 69 $\pm 12.61 ; \mathrm{P}=0.007$ ). Furthermore, ASXL1-mutant/TN patients exhibited a higher number of PLT than ASXL1/JAK2 V617F-double mutant patients (data not shown). 

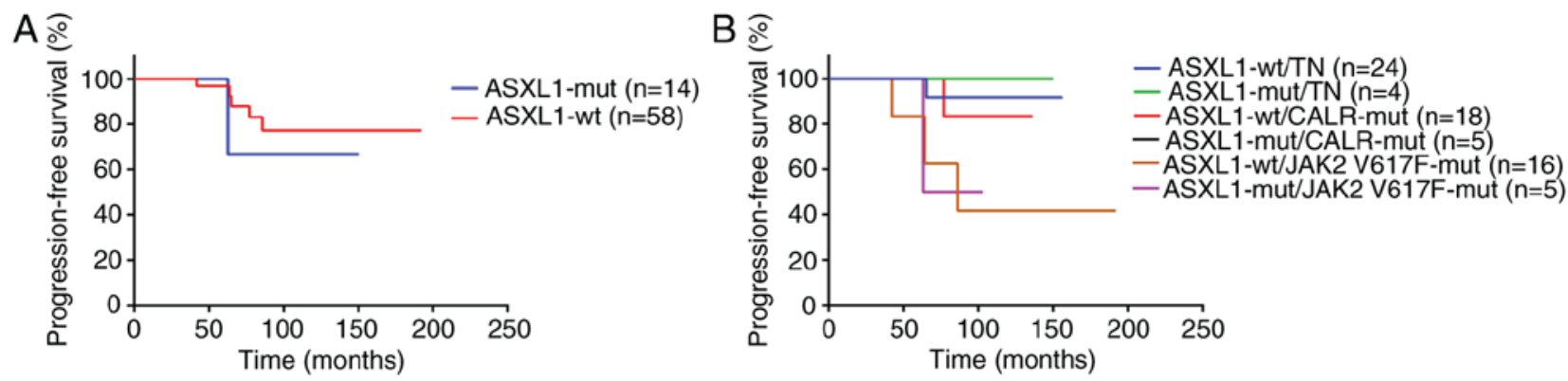

Figure 1. Kaplan-Meier survival curves displaying the progression-free survival in 72 ET patients stratified by their gene mutational status. ET patients were categorized based on $(\mathrm{A})$ the mutational status of ASXL1 $(\mathrm{P}=0.590)$ and $(\mathrm{B})$ the mutational status of ASXL1 and concomitant mutations of JAK2 V617F and CALR, or TN status. ET, essential thrombocythemia; wt, wild-type; mut, mutated; TN, triple-negative; JAK, Janus kinase; CALR, calreticulin; ASXL1, additional sex combs like 1 .

A

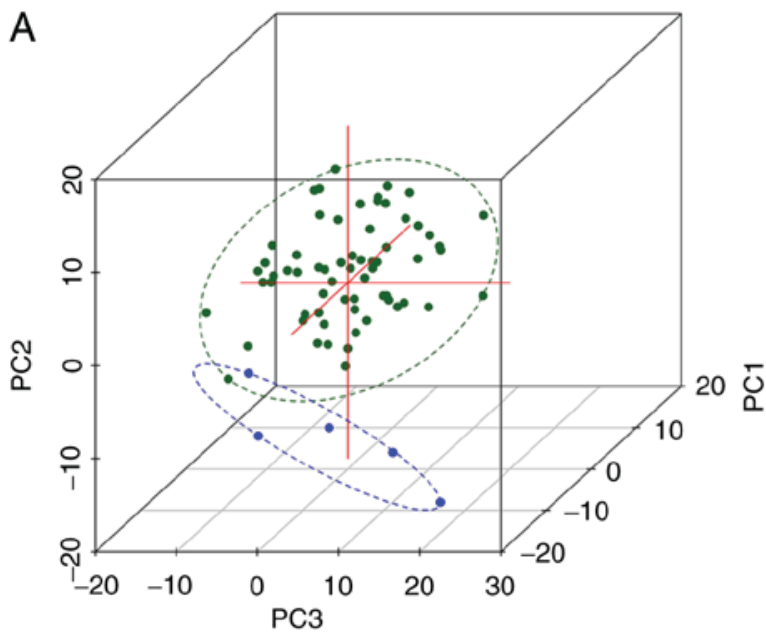

B

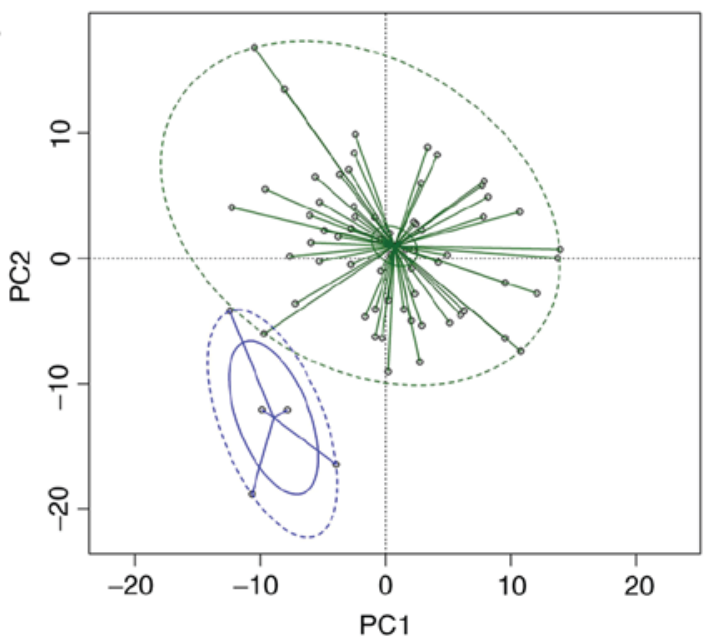

Figure 2. (A) Three-dimensional graph of the first three PCs of HB, WBC and PLT by PCA; (B) graph of the first two PCs of HB, WBC and PLT by PCA. Green points represent stable ET patients, blue points represent patients with progressive ET. Green and blue ellipses are the 95\% confidence ellipses of patients with stable ET and progressive ET, respectively. The two statuses are clearly distinguished on the graphs and are significantly different $(\mathrm{P}=0.001)$. PCA, principal component analysis; HB, hemoglobin; WBC, white blood cells; PLT, platelets; ET, essential thrombocythemia.

$P F S$. It has been previously reported that in a proportion of patients ET may develop into MF, PV, MDS or AML (25-29). Therefore, the present study further assessed this transformation in ET patients. Of note, ET did not transform to leukemia in any of the patients during the observation period. However, in 1 ET patient with and 4 patients without ASXL1 mutation, the disease transformed to $\mathrm{PV}$, and in 1 patient with wild-type ASXL1, it transformed to MF. Statistical analysis indicated no significant difference in PFS between ASXL1-mutant and ASXL1-wt patients ( $\mathrm{P}=0.590$; Fig. 1A). While in the further analysis, the PFS in the ASXL1-wt/JAK2 V617F-mutant group was significantly lower than the ASXL1-wt/TN group $(\mathrm{P}=0.026$; Fig. 1B). Furthermore, multivariable Cox proportional hazards regression analyses were performed to identify possible predictors for PFS. Of note, thrombosis [hazard ratio $(\mathrm{HR})=13.938$; 95\% confidence interval (CI), 4.408-17.696; $\mathrm{P}=0.037]$, HB $(\mathrm{HR}=1.027 ; 95 \% \mathrm{CI}, 1.002-1.053 ; \mathrm{P}=0.043)$ and PLT (HR=0.995; 95\% CI, 0.989-1.000; $\mathrm{P}=0.041)$ were identified as independent predictors for PFS in ET patients. HB, WBC and PLT were significantly different between patients with progressive ET, which could progress to PV, post-ET myelofibrosis and myelodysplastic syndrome or acute leukemia, and those with stable ET according to PERMANOVA analysis
( $\mathrm{P}=0.001 ;$ Fig. 2). No significant difference in disease progression was identified between ASXL1-mutant and ASXL1-wt cohorts (Table VII).

Response to treatment. Next, the present study investigated whether ASXL1 mutations affect the response of ET patients to drug treatments. All patients enrolled in the study received either hydroxyurea, interferon- $\alpha$ or combination therapy of hydroxyurea and interferon- $\alpha$. Statistical analyses indicated that the entire ASXL1-mutant cohort had a similar overall response rate (ORR) to the abovementioned treatments to that of the ASXL1-wt cohort. Additionally, the low-, intermediateand high-risk ASXL1-mutant groups also exhibited a similar ORR to the treatments compared with that of their wild-type counterparts. There was no statistically significant difference between the ASXL1-mutant and ASXL1-wt cohort in CR, PR or NR (Table IV).

\section{Discussion}

Recently, ASXL1 mutations have been demonstrated in the majority of hematological diseases, including MDS, AML, MDS/MPN and CMML (8-13). In Western countries, the 
Table VII. Disease progression compared between essential thrombocythemia patients stratified according to their mutational status of ASXL1 in combination with that of other genes.

\begin{tabular}{|c|c|c|c|c|c|c|}
\hline Parameter & $\begin{array}{l}\text { ASXL1-mutant } \\
\text { vs. ASXL1-wt }\end{array}$ & $\begin{array}{c}\text { ASXL1-wt/TN } \\
\text { vs. ASXL1-wt/ } \\
\text { CALR-mutant } \\
\text { vs. ASXL1-wt/ } \\
\text { JAK2617F-mutant }\end{array}$ & $\begin{array}{c}\text { ASXL1-mutant/TN } \\
\text { vs. ASXL1-mutant/ } \\
\text { CALR-mutant } \\
\text { vs. ASXL1-mut/ } \\
\text { JAK2 617F-mutant }\end{array}$ & $\begin{array}{l}\text { ASXL1-wt/TN } \\
\text { vs. } \\
\text { ASXL1-mutant/ } \\
\text { TN }\end{array}$ & $\begin{array}{c}\text { ASXL1-wt/ } \\
\text { CALR-mutant } \\
\text { vs. } \\
\text { ASXL1-mutant/ } \\
\text { CALR-mutant }\end{array}$ & $\begin{array}{c}\text { ASXL1-wt/ } \\
\text { JAK2617F-mutant } \\
\text { vs. } \\
\text { ASXL1-mutant/ } \\
\text { JAK2617F-mutant }\end{array}$ \\
\hline $\begin{array}{l}\text { Disease } \\
\text { progression }\end{array}$ & $\begin{array}{r}5 / 58(8.6) \\
\text { vs. } 1 / 14(7.1)\end{array}$ & $\begin{array}{r}1 / 24(4.2) \\
\text { vs. } 1 / 18(5.6) \\
\text { vs. } 3 / 16(18.8)\end{array}$ & $\begin{array}{r}0 / 4(0) \\
\text { vs. } 0 / 5(0) \\
\text { Vs. } 1 / 5(20)\end{array}$ & $\begin{array}{l}1 / 24(16.7) \\
\text { vs. 0/4 (0) }\end{array}$ & $\begin{array}{l}1 / 18(5.6) \\
\text { vs. } 0 / 5(0)\end{array}$ & $\begin{array}{l}3 / 16(18.8) \\
\text { vs. } 1 / 5(20)\end{array}$ \\
\hline P-value & 1.000 & 0.310 & 1.000 & 1.000 & 1.000 & 1.000 \\
\hline
\end{tabular}

Values are expressed as n/total (\%). TN, triple-negative; JAK, Janus kinase; CALR, calreticulin; ASXL1, additional sex combs like 1; wt, wild-type.

incidence of ASXL1 mutations in ET patients is $~ 5.6 \%$ (16). However, the present study detected ASXL1 mutations in $19.4 \%$ of Chinese ET patients. This percentage is also higher than that reported by Shen et al (30), who determined the occurrence of ASXL1 mutations in ET patients to be $\sim 6.1 \%$. This difference may be due to different genetics and environments.

It has been indicated that ASXL1 gene mutations in hematological diseases include frameshift, point and nonsense mutations. Of note, frameshifts account for $>50 \%$ of ASXL1 mutations. However, the present study indicated that the most frequent ASXL1 mutation in Chinese ET patients is c.G1954A with an incidence of $19.4 \%$. In addition, point mutation [c.G1954A(p.Gly652Ser)] was the only mutation observed in the present study. The frameshift mutation, c.1934dupG, was not detected in the Chinese ET patients. The results of the present study were in accordance with those of Abdel-Wahab et al (31), where the ASXL1 gene was sequenced from patients with multiple types of myeloid malignancies in paired tumor DNA and DNA extracted from buccal tissue. In the latter study, the frameshift mutation of ASXL1 [c.1934dupG(p.Gly646TrpfsX12)] was identified in an 8-bp guanine mononucleotide repeat sequence, and it was therefore speculated that the frameshift transformation was not a true somatic mutation, but an artifact of PCR amplification. Aforementioned mutation was no identified in the present study; this may be due to differences in genetics and the environments between the two studies. Indeed, the most commonly reported mutation of ASXL1 (c.1934dupG) was detected in $>25 \%$ of healthy volunteers (31), suggesting that the frameshift mutation in ASXL1 may not be an actual somatic mutation. Furthermore, another study revealed that $\sim 0.2 \%$ (1/491) of normal control samples harbored a frameshift mutation, suggesting that this mutation may not be specific for ET patients (32). The present study determined that compared with the ASXL1-wt group, ASXL1-mut patients had obvious propensities for thrombotic events, suggesting that an ASXL1 mutation is a factor associated with poor prognosis. However, due to the low death rate of ET patients enrolled in the present study, no difference in OS and PFS was identified between these two groups. As the precise functional role of ASXL1 in the pathogenesis of ET remains elusive, future studies are planned to uncover it using in vitro experiments. Furthermore, more clinical ET samples will be collected from multiple centers and analyzed in a future study.

Thrombohemorrhagic events are regarded to be among the most severe complications in ET patients (33-36). In the present study, ASXL1-mutant cohorts have demonstrated propensities for thrombotic events. Therefore, blocking of ASXL1 mutations may be a novel potential strategy to prevent the occurrence of thrombohemorrhagic events in ET patients in the clinic.

\section{Acknowledgements}

The authors would like to thank Dr Pan-wen Wang (Department of Health Sciences Research, Mayo Clinics, Scottsdale, AZ, USA) for the amendments made to the present study.

\section{Funding}

The present study was supported by grants from the National Natural Science Foundation of China (grant nos. 81670125 and 81500151).

\section{Availability of data and materials}

The datasets used and/or analyzed during the current study are available from the corresponding author on reasonable request.

\section{Authors' contributions}

YBN and MS performed the major experiments. CKH calculated and analyzed the clinical data. MKJ, FLZ, SYW, YZ, LL, HS, TTH, PL and YX collected clinical samples and took part in the discussion of the project. LS and XLZ designed the study and wrote the manuscript.

\section{Ethics approval and consent to participate}

Informed written consent was obtained from patients prior to sample collection, in accordance with the Declaration of Helsinki, and clinical research was approved by the Ethics 
Committee of Zhongnan Hospital of Wuhan University (Wuhan, China) and the Fifth Hospital of Wuhan (Wuhan, China).

\section{Consent for publication}

Not applicable.

\section{Competing interests}

The authors declare that they have no competing interests.

\section{References}

1. Kang MG, Choi HW, Lee JH, Choi YJ, Choi HJ, Shin JH, Suh SP, Szardenings M, Kim HR and Shin MG: Coexistence of JAK2 and CALR mutations and their clinical implications in patients with essential thrombocythemia. Oncotarget 7: 57036-57049, 2016.

2. Barosi G, Birgegard G, Finazzi G, Griesshammer M, Harrison C, Hasselbalch HC, Kiladjian JJ, Lengfelder E, McMullin MF, Passamonti F, et al: Response criteria for essential thrombocythemia and polycythemia vera: Result of a European LeukemiaNet consensus conference. Blood 113: 4829-4833, 2009.

3. Barbui T, Thiele J, Gisslinger H, Finazzi G, Vannucchi AM and Tefferi A: The 2016 revision of WHO classification of myeloproliferative neoplasms: Clinical and molecular advances. Blood Rev 30: 453-459, 2016.

4. Micol JB and Abdel-Wahab O: The Role of Additional Sex Combs-Like Proteins in Cancer. Cold Spring Harb Perspect Med 6: pii: a026526, 2016.

5. Katoh M: Functional and cancer genomics of ASXL family members. Br J Cancer 109: 299-306, 2013.

6. Abdel-Wahab O, Adli M, LaFave LM, Gao J, Hricik T, Shih AH, Pandey S, Patel JP, Chung YR, Koche R, et al: ASXL1mutations promot myeloid transformation through loss of PRC2-mediated gene repression. Cancer Cell 22: 180-193, 2012.

7. Huang J, Ge M, Lu S, Shi J, Li X, Zhang J, Wang M, Yu W, Shao Y, Huang Z, et al: Mutations of ASXL1 and TET2 in aplastic anemia. Haematologica 100: e172-e175, 2015.

8. Yoshizato T, Dumitriu B, Hosokawa K, Makishima H, Yoshida K, Townsley D, Sato-Otsubo A, Sato Y, Liu D, Suzuki H, et al: Somatic mutations and clonal hematopoiesis in aplastic anemia N Engl J Med 373: 35-47, 2015.

9. Gelsi-Boyer V, Trouplin V, Adélaïde J, Bonansea J, Cervera N, Carbuccia N, Lagarde A, Prebet T, Nezri M, Sainty D, et al: Mutations of polycomb-associated gene ASXL1 in myelodysplastic syndromes and chronic myelomonocytic leukaemia. Br J Haematol 145: 788-800, 2009.

10. Gelsi-Boyer V, Brecqueville M, Devillier R, Murati A, Mozziconacci MJ and Birnbaum D: Mutations in ASXL1 are associated with poor prognosis across the spectrum of malignant myeloid diseases. J Hematol Oncol 5: 12, 2012.

11. Gill H, Leung AY and Kwong YL: Molecular and cellular mechanisms of myelodysplastic syndrome: Implications on targeted therapy. Int J Mol Sci 17: 440, 2016.

12. Vannucchi AM, Lasho TL, Guglielmelli P, Biamonte F, Pardanani A, Pereira A, Finke C, Score J, Gangat N, Mannarelli C, et al: Mutations and prognosis in primary myelofibrosis. Leukemia 27: 1861-1869, 2013.

13. Ferrer-Marin F, Bellosillo B, Martínez-Avilés L, Soler G, Carbonell P, Luengo-Gil G, Caparros E, Torregrosa JM, Besses C and Vicente V: Leukemic transformation driven by an ASXL1 mutation after a JAK2V617F-positive primary myelofibrosis: Clonal evolution and hierarchy revealed by next-generation sequencing. J Hematol Oncol 6: 68, 2013.

14. Shih AH, Abdel-Wahab O, Patel JP and Levine RL: The role of mutations in epigenetic regulators in myeloid malignancies. Nat Rev Cancer 12: 599-612, 2012.

15. Viny $A D$ and Levine RL: Genetics of myeloproliferative neoplasms. Cancer J 20: 61-65, 2014.

16. Milosevic JD and Kralovics R: Genetic and epigenetic alterations of myeloproliferative disorders. Int J Hematol 97: 183-197, 2013.
17. Al Assaf C, Van Obbergh F, Billiet J, Lierman E, Devos T, Graux C, Hervent AS, Emmerechts J, Tousseyn T, De Paepe P, et al: Analysis of phenotype and outcome in essential thrombocythemia with CALR or JAK2 mutations. Haematologica 100: 893-897, 2015.

18. Imai M, Araki M and Komatsu N: Somatic mutations of calreticulin in myeloproliferative neoplasms. Int J Hematol 105: 743-747, 2017.

19. Clinton A and McMullin MF: The Calreticulin gene and myeloproliferative neoplasms. J Clin Pathol 69: 841-845, 2016.

20. Tefferi A: JAK and MPL mutations in myeloid malignancies. Leuk Lymphoma 49: 388-397, 2008.

21. Ji L, Qian M, Wu N and Wu J: Significance of combined detection of JAK2V617F, MPL and CALR gene mutations in patients with essential thrombocythemia. Exp Ther Med 13: 947-951, 2017.

22. Wang J, Zhang B, Chen B, Zhou RF, Zhang QG, Li J, Yang YG, Zhou M, Shao XY, Xu Y, et al: JAK2, MPL, and CALR mutations in Chinese Han patients with essential thrombocythemia. Hematology 22: 145-148, 2017.

23. Zhao S, Zhang X, Xu Y, Feng Y, Sheng W, Cen J, Wu D and Han Y: Impact of JAK2 V617F mutation burden on disease phenotype in Chinese patients with JAK2V617F-positive polycythemia vera (PV) and essential thrombocythemia (ET). Int J Med Sci 13: 85-91, 2016.

24. Barbui T, Finazzi G, Carobbio A, Thiele J, Passamonti F, Rumi E, Ruggeri M, Rodeghiero F, Randi ML, Bertozzi I, et al: Development and validation of an International Prognostic Score of thrombosis in World Health Organization-essential thrombocythemia (IPSET-thrombosis). Blood 120: 5128-5133, 2012.

25. Paschka P, Schlenk RF, Gaidzik VI, Herzig JK, Aulitzky T, Bullinger L, Späth D, Teleanu V, Kündgen A, Köhne CH, et al: ASXL1 mutations in younger adult patients with acute myeloid leukemia: A study by the German-Austrian Acute Myeloid Leukemia Study Group. Haematologica 100: 324-330, 2015.

26. Passamonti F, Maffioli M, Merli M, Ferrario A and Caramazza D: Clinical predictors of outcome in MPN. Hematol Oncol Clin North Am 26: 1101-1116, 2012.

27. Barbui T, Thiele J, Passamonti F, Rumi E, Boveri E, Ruggeri M, Rodeghiero F, d'Amore ES, Randi ML, Bertozzi I, et al: Survival and disease progression in essential thrombo-cythemia are significantly influenced by accurate morphologic diagnosis: An international study. J Clin Oncol 29: 3179-3184, 2011.

28. Shrestha R, Giri S, Pathak R and Bhatt VR: Risk of second primary malignancies in a population-based study of adult patients with essential thrombocythemia. World J Clin Oncol 7: 324-330, 2016.

29. Suleiman Y, Dalia S, Liu JJ, Bowers JW, Padron E, Lancet JE, Fulp W, Moscinski LC, Komrokji RS, Zuckerman KS and Zhang L: Clinical prognostic factors and outcomes of essential thrombocythemia when transformed to myelodysplastic syndromes and acute myeloid leukemia. Leuk Res 42: 52-58, 2016.

30. Shen H, Chao H, Ding Z, Feng Y, Cen J, Pan J, He J, Zhou M, Chen Z and Chen S: CALR and ASXL1 mutation analysis in 190 patients with essential thrombocythemia. Leuk Lymphoma 56: 820-822, 2015.

31. Abdel-Wahab O, Kilpivaara O, Patel J, Busque L and Levine RL: The most commonly reported variant in ASXL1 (c.1934dupG;p. Gly646TrpfsX12) is not a somatic alteration. Leukemia 24: 1656-1657, 2010.

32. Stein BL, Williams DM, O'Keefe C, Rogers O, Ingersoll RG, Spivak JL, Verma A, Maciejewski JP, McDevitt MA and Moliterno AR: Disruption of the ASXL1 gene is frequent in primary, post-essential thrombocytosis and post-polycythemia vera myelofibrosis, but not essential thrombocytosis or polycythemia vera: Analysis of molecular genetics and clinical phenotypes. Haematologica 96: 1462-1469, 2011.

33. Rumi E and Cazzola M: How I treat essential thrombocythemia. Blood 128: 2403-2414, 2016.

34. Vainchenker W, Constantinescu SN and Plo I: Recent advances in understanding myelofibrosis and essential thrombocythemia. F1000Res 5: pii: F1000 Faculty Rev-700, 2016.

35. Aruch D and Mascarenhas J: Contemporary approach to essential thrombocythemia and polycythemia vera. Curr Opin Hematol 23: 150-160, 2016.

36. Barbui T,Thiele J,Vannucchi AMand Tefferi A: Myeloproliferative neoplasms: Morphology and clinical practice. Am J Hematol 91: 430-433, 2016.

This work is licensed under a Creative Commons
Attribution-NonCommercial-NoDerivatives 4.0 International (CC BY-NC-ND 4.0) License. 